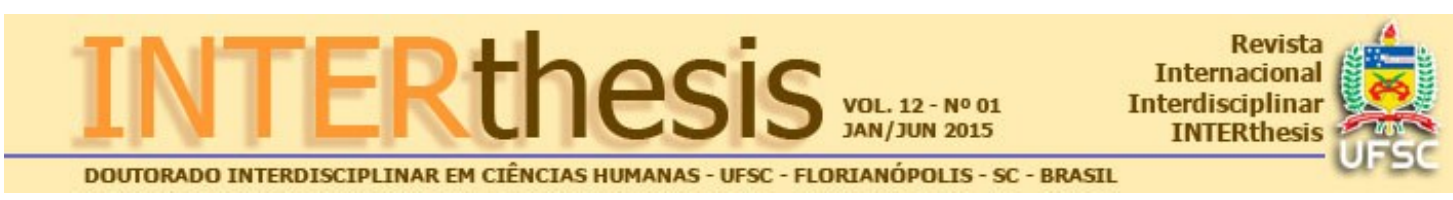

\title{
ADOLESCÊNCIA, MODERNIDADE E A CULTURA DOS DIREITOS
}

\begin{abstract}
Cristiana Carneiro ${ }^{1}$
Leila Maria Amaral Ribeiro ${ }^{2}$

Rita Ippolito 3

Resumo:

O objetivo deste artigo é apresentar uma leitura do surgimento da categoria adolescência, as consequências e desdobramentos que tal perspectiva efetiva na criação de uma cultura de direitos. Nascida no ideário da modernidade, a adolescência traz em seu bojo certa concepção de temporalidade relacionada ao surgimento do individualismo e à valorização do desenvolvimento como trajetória humana. É somente a partir de uma concepção de trajetória necessária à construção do indivíduo autônomo e livre, simbolizado pelo adulto, que se torna possível refletir sobre o adolescente como sujeito de direitos. Portanto, o surgimento da categoria adolescência como objeto de estudos e cuidados enseja também toda uma discussão mais abrangente de direitos e deveres culminando com a ideia de ser adolescente como um direito.
\end{abstract}

Palavras-chave: Adolescência. Modernidade. Individualismo. Liberdade. Direitos.

\section{ADOLESCÊNCIA E UNIVERSALIDADE}

Estudar a construção da adolescência como categoria, a articulando à criação de uma cultura de direitos relaciona-se à possibilidade de pensá-la como parte importante da trajetória de todos, como peça fundamental do desenvolvimento

\footnotetext{
1 Doutora em Psicologia pela Universidade Federal do Rio de Janeiro. Professora Adjunta e coordenadora do Núcleo Interdisciplinar de Estudo e Pesquisa para a Infância e Adolescência Contemporâneas na Faculdade de Educação da Universidade Federal do Rio de Janeiro, Rio de Janeiro, RJ, Brasil. E-mail: cristianacarneiro13@gmail.com

2 Doutora em Psicologia pela Universidade Federal do Rio de Janeiro. Professora Adjunta do Instituto de Psiquiatria da Universidade Federal do Rio de Janeiro, com atuação no Serviço de Psiquiatria da Infância e da Adolescência. Professora do Curso de Especialização em Psiquiatria e Psicanálise com Crianças e Adolescentes; coordenadora do Programa Violência Doméstica e Psicanálise, Rio de Janeiro, RJ, Brasil. Email: leirib@gmail.com

${ }^{3}$ Pedagogia e Língua e Literatura Italiana pela Universitá Statale di Palermo, Itália. Especialista na área da Infância e Juventude, em Psicologia do Desenvolvimento Infantil. Atua no Brasil desde 1992, trabalhando em projetos de desenvolvimento infanto-juvenil, e com atuação especifica na área dos direitos humanos de crianças e adolescentes e a educação. Consultora independente para o Ministério da Educação, a Universidade Federal Rural do Rio de Janeiro, a UNESCO, a Casa de Zabelé-PI, projeto da Ação Social Arquidiocesana, entre outros, com atuação em área de educação e inserção social, direitos humanos e responsabilidade social. Email: rita.ippolito@gmail.com
}

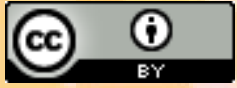


humano. No entanto, a concepção de desenvolvimento humano, a importância da biografia, as representações do foro íntimo como lugar de singularidade e verdade, que hoje nos parecem tácitas, levaram séculos sendo gestadas e construídas. $\mathrm{O}$ trajeto individual da criança para o adulto passou a ser uma preocupação a partir da modernidade, e ensejou também toda uma discussão mais abrangente de direitos e deveres, políticas específicas, garantia dos direitos. Alguns aspectos da modernidade criaram as condições para que a trajetória passasse a ser objeto de interesse, sendo o individualismo um ponto chave, como discorreremos mais adiante. Outro aspecto importante foi a centralidade da razão e o ideal de adulto racional, livre e autônomo. No presente trabalho visamos percorrer a construção da categoria como fundamento para que se possa pensar numa cultura de direitos da infância e adolescência.

Encontramos uma ancoragem da construção da categoria adolescência no ideal de liberdade articulado ao individualismo na modernidade. A adolescência surge com a tarefa de individualizar o homem para que esse seja capaz de levar adiante o projeto moderno, no que concerne ao ideal de liberdade e autonomia. Mas, como a adolescência surge como um tempo da vida humana, articulada a uma faixa etária, ela também nos diz sobre as concepções de tempo que subjaziam esse projeto.

Primeiramente, não é demais lembrarmos, que a adolescência enquanto uma categoria distinta do adulto e da criança é uma invenção recente que chega com a modernidade, pois foi apenas a partir do final do século XVIII que inicialmente apareceu, vindo, somente, a se difundir amplamente no século $X X$. Em relação a certa localização, aproximamos o termo modernidade ao uso feito por Giddens (1991) onde "modernidade refere-se a estilo, costume de vida ou organização social que emergiram na Europa a partir do século XVII e que ulteriormente se tornaram mais ou menos mundiais em sua influência" (p. 11). Para ele, a modernidade teria como marca um esforço global de produção e controle, cujas quatro principais dimensões são: o industrialismo, o capitalismo, a industrialização da guerra e a vigilância de todos os aspectos da vida social. Em relação ao enfoque por nós destacado na modernidade, privilegiamos dois grandes eixos, a "confiança na razão", portanto na centralidade da razão como instrumento de libertação do homem, e o surgimento do individualismo como fundamento do nascimento da noção de sujeito (TOURAINE, 2002, p. 5). 
Ariès (1960), por sua vez, nos mostra que se a categoria de criança possuía um estatuto totalmente diverso do atual e que a de adolescente praticamente não existia. A média de vida antes da modernidade era tão menor, a mortalidade infantil tão corriqueira, e tão necessária à força de trabalho, que logo que a criança fosse capaz de participar da vida produtiva, lá estava ela inserida no mundo dos adultos sem todas as diferenças que a modernidade impôs. O jovem, que nós chamaríamos de adolescente hoje, por sua vez, tendo um corpo apto à reprodução e participando da vida produtiva, não era nada além do que um adulto jovem. Ele observa que o prolongamento da escolaridade até os dezoito ou vinte anos - apenas nas classes privilegiadas -, ajudou a diferenciar essa nova fase da idade adulta e da infância. Mas, ele assinala que mesmo depois desta prática ter sido difundida, a infância e a adolescência continuaram a ser confundidas, pois "dentro do mundo escolar, o adolescente era separado do adulto e confundido com a criança, com a qual compartilhava a humilhação do castigo corporal" (ARIĖS, 1960, p. 262), sendo assim considerado, de certa forma, também como criança. Somente no século dezoito, quando os exércitos começaram a tentar atrair os jovens para suas fileiras é que algo semelhante ao moderno conceito de adolescência começou a surgir (ARIĖS, 1960). Isto porque a estes jovens esperava-se certa exigência que se assemelhava ao adulto, no entanto a instrução era oferecida e entendida como fundamental - algo que os assemelhava à criança-, criando um campo híbrido que os situava entre estes pólos.

Nos tempos que precederam a modernidade ocidental, (e em certos povos até hoje), o mundo social criava ritos que serviam como demarcação da passagem do mundo da criança ao mundo adulto. Os ritos de passagem serviam como momento específico, demarcado, circunscrito, de assunção da posição de adulto no mundo social, e, portanto efetuavam simbolicamente uma passagem reconhecida socialmente da criança para o adulto. Não havia porque se pensar em adolescência, já que esses mecanismos socialmente construídos garantiam a passagem da criança diretamente ao estatuto de adulto. Efetuados os rituais, legitimada estava a passagem, e o reconhecimento do novo adulto pela comunidade. Nesse sentido, nós podemos entender que até as sociedades ocidentais modernas e industrializadas se constituírem, a passagem da criança ao adulto era compreendida de forma muito mais direta, sem uma delonga temporal, como a compreendemos hoje. 
Se, então, a adolescência surge recentemente na história, o que o termo veio ilustrar? O que se entende por adolescência?

Herbert (1991), em seu livro Convivendo com Adolescentes, se pergunta se existiria algo típico na adolescência. Haveria a natureza da adolescência? Ou melhor, o que mais precisamente chamamos de adolescência? Existiria algo comum nas inúmeras adolescências? Para ele, as noções de infância e idade adulta talvez sejam mais claras, posto que à criança conferimos um lugar de dependência, e ao adulto esperamos a independência, ou seja, que sejam capazes de cuidar de si mesmos. Mas, em "algum ponto entre a imaturidade da infância e a esperada maturidade da idade adulta residem os seis ou sete anos a que chamamos adolescência. Que há (e haverá) um estágio de transição entre a 'irresponsabilidade' e a 'responsabilidade' é coisa aceita desde a época de Aristóteles" (HERBERT, 1991 , p. 16); mas a questão é que no mundo moderno ocidental, em nossas sociedades industriais e urbanas, não dispomos de ritos de iniciação como na antiguidade, de rituais que demarquem nitidamente, social e fisicamente, a entrada do púbere no território da idade adulta. Não há, no mundo ocidental contemporâneo, um único ritual que guarneça as crianças com algum sinal claro de que deixaram a infância (HERBERT, 1991).

Não havendo uma demarcação simbólica nítida da entrada no mundo adulto, encontramos essa passagem, no mundo contemporâneo, de uma maneira muito mais difusa, delongada, pouco demarcada. A iniciação na idade adulta, no mundo moderno, se comporia de vários pequenos eventos, pouco nítidos, que acumulados indicariam que a infância acabou (HERBERT, 1991). Esses pequenos eventos seriam muito mais da ordem de processos psicológicos (como individualização, assunção de uma identidade própria, escolha sexual, entre outros), do que por um mecanismo social especificamente destinado a este fim, como os ritos de passagem. O único aspecto universalizável desse momento da vida seria a puberdade.

A puberdade seria o fenômeno biológico pelo qual, de maneira generalizável, deveriam passar os seres humanos, onde ocorreriam mudanças físicas e fisiológicas a partir da ação dos hormônios. Momento de eclosão dos caracteres sexuais secundários, que culminaria na aptidão biológica de homens e mulheres a reproduzir. Teríamos assim que a puberdade é universal, enquanto a adolescência é histórica, porque circunscrita a determinado tempo e lugar. 
O trabalho de Mead (1984), Adolescência, sexo e cultura em Samoa, foi um marco para a desconstrução da adolescência como conceito universal. A partir de um estudo minucioso na ilha de Tau, ela declara que o único aspecto comum da produção da adolescência em Samoa e da adolescência nos Estados Unidos era que, numa determinada idade, apareciam mudanças corporais. A entrada na puberdade em Samoa era um feito fisiológico, não revestido absolutamente de tensões de caráter psíquico. Segundo sua análise, lá os ritmos culturais eram mais fortes e coercitivos que os fisiológicos, cobrindo-os e deformando-os (MEAD, 1984, p. 3). Indo nessa direção, se a puberdade é um fenômeno universal, a adolescência não o é.

Se houve um adiamento do momento no qual a criança deveria assumir a posição do adulto, foi porque justamente a própria visão do que era ser uma criança ou um adulto também veio a se modificar na modernidade. Tomando-os como objetos diferenciados, Ihes foi atribuído um mundo psíquico particular, foco de interesse do espírito científico nascendi. Nesse sentido, foi somente a partir de uma nova compreensão do próprio humano, onde seu interior passou a ser objeto de interesse, atenção e importância, que foi possível o surgimento da categoria de adolescência. Mas, esse interior não se definia pelo mundo espiritual - preocupação milenar da religião - e sim pela suposição de que deveria haver processos psíquicos específicos aos seres humanos nas diferentes idades. Ou melhor, o termo adolescência surgiu em referência à processos psicológicos, tanto é que não suplantou a categoria de puberdade. Sendo assim, se a puberdade está referida a processos biológicos, por sua vez, a adolescência está referida a processos psicológicos. Assim, a expansão da passagem criança-adulto se deu porque atribuiu-se a ela certos processos psicológicos que deveriam se dar antes da assunção à posição de adulto.

Isso só foi possível a partir do novo olhar que a modernidade conferiu ao próprio homem, posto que se o que se esperava de um adolescente é que adquirisse independência psicológica dos pais, individualizando-se. Tal expectativa se deve ao fato de que na modernidade tornar-se individual passou a ser um processo valorizado. $O$ homem moderno passa assim a ocupar o interesse de si próprio, se toma como objeto, o que delineia os primórdios do individualismo (FIGUEIREDO, 1992, p. 33). 


\section{INDIVIDUALISMO E LIBERDADE}

O conceito de individualismo, longe de ser homogêneo, apresenta diferentes óticas de interpretação, tendo sido pioneiramente definido por Tocqueville em De la Democratie en Amérique (1835) onde estava ligado ao pensamento democráticoliberal. Para ele, o individualismo surge e se desenvolve sobre uma base de condições igualitárias para os indivíduos. Posteriormente, Dumont (1985) retoma a discussão de Tocqueville para desconstruir uma concepção universal de indivíduo ressaltada em sua obra, ao mostrar que os modelos individualistas são variáveis, como por exemplo, no modelo indiano, onde a individualização será possível através da busca espiritual (idem, p.38).

A questão da igualdade, por sua vez, embasava outro princípio, direito essencial referido desde a Declaração dos Direitos do Homem, que era a liberdade de consciência (DUMONT, 1985, p. 111). Nesse sentido, a partir do século XVIII, a liberdade tornou-se uma das demandas universais do indivíduo. A liberdade individual, a possibilidade de exercer um domínio, através da instrumentalidade da razão administrar coisas e governar os homens. Locke valorizou o entendimento para dirigir as ações, liberdade da vontade, liberdade de agir, trabalho e direito de propriedade. A lei deve proteger a liberdade de agir, de empreender e de possuir. Hobbes e Rousseau defenderam o direito de consciência, o pensamento, a aprendizagem, como formas legítimas de conhecimento, o contrato como regulador social de garantiria da igualdade. A liberdade da submissão ao divino na descoberta da consciência de si, que se preocupa com essa forma mestra que pode ser chamada personalidade individual, como diz Montaigne, polo de libertação da verdade como essência divina (TOURAINE, 2002). Enfim, a liberdade se faz presente em várias esferas: na política os ideais da Revolução Francesa, na economia surge o conceito de livre competição, na filosofia o conceito do valor moral em Kant. Mas, aqui, o que é importante ressaltarmos é que essa possibilidade de liberdade estava intrinsecamente ligada ao exercício do pensamento, porque somente através dele seria possível conhecer a verdade, que não estaria mais fora do mundo, porém diria respeito à consciência de si. Nesse sentido, a liberdade no pensamento moderno, nas suas diferentes concepções, estava articulada ao indivíduo, porque seria promovida através dele, a partir dele, fosse contra a opressão social, através da ação, fosse contra seu próprio desconhecimento 
aprisionante, através da razão. O indivíduo desta forma passa então a ser responsável pela liberdade, o que na Antiguidade e na Idade Média era impensável. Porque tanto no pensamento cristão, quanto no pensamento politeísta, a liberdade estava fora do indivíduo, ela se situava fora do espaço mundano, era uma dádiva do, ou, dos deuses. Por ser um atributo que não the pertencia, não poderia ser autoexercido, pois estava fora dele. O juízo de quanto, como, onde, um indivíduo poderia ser livre, permanecia exterior, em Deus, ou no soberano, até porque não existia a compreensão de um indivíduo destacado, o homem era parte integrante do universo. Justamente essa questão da liberdade articulada ao individualismo, modifica a compreensão do destino, que passará a ser considerado como concernente ao indivíduo, e não mais estritamente remetido à exterioridade.

O pensamento cristão não deve ser entendido como homogêneo. Embora esse viés fosse predominante, para alguns pensadores apareciam modificações. Santo Agostinho, por exemplo, defendia que o homem contemplaria Deus não apenas pela beleza de sua obra, mas voltando-se para si mesmo, para sua interioridade, a alma, criada por Deus à sua imagem. Diz-nos Touraine (2002), comentando as confissões agostinianas, que "Agostinho escreveu suas Confissões porque a memória é uma atividade do espírito, portanto da razão, e permite a passagem do exterior para o interior" (p. 44). Duarte (1983) enfatiza que o Cristianismo, embora no registro da exterioridade, já sublinhava alguma menção à interioridade, contribuindo, assim, para alicerçar três pontos essenciais que posteriormente seriam caros ao individualismo: verdade, interioridade e vontade. Através do mito de Adão e Eva ele nos mostra que a relação conflituosa entre desejo e pecado está remetida a certa interioridade da consciência cristã, fazendo com que a ideia de desejo interior se relacionasse à verdade particular do sujeito. Essa visão nos mostra que, embora nada comparado ao individualismo moderno pudesse ser sublinhado naquela época, alguns pontos demarcavam o que viria a ser substrato da instituição do individual.

O desencantamento ${ }^{4}$ do mundo, que é correlato ao surgimento do individualismo, ao trazer o que era do domínio da exterioridade para a interioridade, deslocou a fixidez de um destino pré-dado por forças exteriores, e começou a

\footnotetext{
4 A ideia de desencantamento do mundo está remetida ao pensamento weberiano onde a modernidade não opera uma eliminação do sagrado, mas a substituição de um ascetismo fora do mundo por um ascetismo dentro do mundo.
}

R. Inter. Interdisc. INTERthesis, Florianópolis, v.12, n.1, p.176-191, Jan-Jun. 2015 
creditar seus feitos aos próprios homens. Nesse sentido, uma das consequências da modernidade, através do individualismo, foi possibilitar a constituição de um mundo subjetivo, interiorizado, substrato do apelo à liberdade pessoal. Afrouxados os vínculos com um destino previamente determinado, tanto pela injunção divina quanto pela posição do indivíduo no quadro coletivo e hierárquico, o sujeito moderno abre espaço para escolhas e projetos individualizados, para destinos idiossincráticos (FIGUEIREDO, 1992, p. 29).

Um dos traços característicos da modernidade em relação à ideia de indivíduo é acreditá-la como "autofundante" (FIGUEIREDO, 1992, p. 35), ou seja, atribuir-lhe, de certa forma, uma responsabilidade na sua própria constituição. Nesse sentido, a concepção moderna de indivíduo surgiu intrinsecamente articulada a um ideário de exercício de liberdade que, a partir de então, passou a ser atribuído à interioridade, ao próprio indivíduo. É nessa ótica que Touraine (2002) vai dizer que se a modernidade foi revolucionária, o foi, sobretudo como apelo à libertação. Para ele, a crítica antimodernista extremada, muitas vezes, ao adotar uma perspectiva nostálgica da tradição, esquece o grito de liberdade que também estava no âmago do pensamento moderno.

Portanto o que entrou em jogo, com o ideal de liberdade possibilitado pelo individualismo, foi o rompimento com um ideário de conformidade predominante nas concepções onde o homem se compreendia impossibilitado de gerir a própria vida. Se sair do Ser era entrar para a existência, ou melhor, deslocar um poder absolutamente exterior para um poder que agora dizia respeito ao sujeito, apropriável e interiorizável, simbolizava também a importância em se ter uma história de vida mais particularizada, referida ao domínio subjetivo. Assim, a narrativa individual, idiossincrática da biografia passou a ser cada vez mais valorizada. Foucault (1992) fazendo uma comparação entre a escrita de si na antiguidade e na modernidade aponta como nesta última a questão da identidade passa a ocupar um lugar central.

O pensamento racionalista, calcado no historicismo, passou a se interessar pela história individual, justamente porque esta também nos informaria sobre as leis da evolução histórica, lançando luz sobre o destino humano. Portanto, era preciso se debruçar sobre 0 indivíduo, entender os diferentes momentos da sua vida. $A$ biografia pessoal passou a ser, de forma muito mais contundente, objeto de atenção, de novas práticas, de novos questionamentos. Nesse sentido, de forma gradual e 
paulatina nas sociedades ocidentais modernas, foi sendo enfatizada a dimensão subjetiva do homem, forjando uma consciência de si enquanto universo único "dotado de uma dimensão interior insondável e articulada por uma imbricação entre subjetividade, sexualidade e unidade interior" (BEZERRA JÚNIOR, 1989, p. 222). Isso é importante por ser justamente a partir dessa nova atenção à biografia individual que surgiram os questionamentos e o empenho científico sobre como uma criancinha se tornaria esse homem racional, tão caro à modernidade. Ou melhor, esse novo homem nascido no ideário moderno, que não estava mais condicionado totalmente pelas injunções dos deuses e pelos acasos biológicos. Tratava-se de um homem que, não só, tinha construído a ciência, mas, a tinha como guia, e que acreditava através dela poder finalmente vencer a natureza e as determinações individuais. A partir desse cenário deveria ele esforçar-se ao máximo, para através da razão conseguir esse feito.

\section{ADOLESCÊNCIA, DESENVOLVIMENTO E UMA CULTURA DE DIREITOS}

Essa herança do projeto moderno, que é a possibilidade do indivíduo se colocar como ator, sentir-se participante da sua história pessoal, portanto, contra um destino exterior é um dos seus maiores legados. A liberdade ancorada sobre a idéia do futuro como um vir-a-ser, mas sem um destino já delineado, incrementa os questionamentos sobre o desenvolvimento humano (BEZERRA JÚNIOR, 2000). Nesse cenário a adolescência surgiu como categoria no intuito de instaurar um percurso do desenvolvimento entendido como um sentido crescente, da infância à senescência que é explicitado no próprio significado do termo, pois "a palavra 'adolescência' vem do verbo latino adolescere, que significa 'crescer' ou 'crescer para a maturidade" (HURLOCK, 1979, p. 2). A adolescência adquire assim um lugar de passagem para a vida adulta que é a etapa entendida como mais madura ou mais evoluída.

As ciências psicológicas passaram, então, a se preocupar com esse trajeto individual da criança para o adulto. É nessa direção que foi construída a ideia de desenvolvimento, de que a criança deveria crescer, não só de tamanho, mas intelectualmente, que deveria tornar-se mais forte, instruir-se. Paralelamente ao ideário da importância desta trajetória, começam a surgir as inquietações em como garanti-la. Ou melhor, se é importante a trajetória de passagem da criança ao adulto R. Inter. Interdisc. INTERthesis, Florianópolis, v.12, n.1, p.176-191, Jan-Jun. 2015 
é importante que possamos garanti-la para o maior número de crianças, numa visão democrática de direitos para todos. Portanto o surgimento da categoria adolescência como objeto de estudos e cuidados enseja também toda uma discussão mais abrangente de direitos e deveres, políticas específicas, garantia dos direitos.

Criar uma cultura de direitos humanos passa pela construção da ideia de igualdade entre os seres, portanto o conceito de direitos humanos universais é uma ideia unificadora que nos torna semelhantes independentemente de nossas diferenças, ao mesmo tempo que torna cada um, com suas diferenças, importante (SEM, 2008). Neste sentido o conceito de direitos humanos é central em nossa humanidade e organiza o que chamamos hoje de civilização. O exercício da cidadania requer o conhecimento dos deveres e das responsabilidades de cada cidadão, bem como contratos e convenções que cada sociedade faz em termos de ações permitidas ou proibidas. No entanto, somente no século XX, após as duas guerras mundiais, que a discussão dos direitos adquiriu uma amplitude universalizada. Essa compreensão culminou na assinatura, em 10 de dezembro de 1948, da Declaração Universal dos Direitos Humanos, aprovada pela Assembleia Geral das Nações Unidas. Na ocasião foi assinada, também, a Convenção Internacional sobre a prevenção e punição do crime de genocídio. Esses documentos podem ser considerados marcos inaugurais da nova fase histórica para a discussão e o entendimento sobre os Direitos Humanos. No entanto, ainda que o debate sobre os direitos humanos faça parte das discussões históricas sobre os direitos dos cidadãos, quanto aos direitos de crianças e adolescentes a discussão é bastante recente, sobretudo no Brasil. Apenas com a criação do Estatuto da Criança e do Adolescente em 1990, estes segmentos passaram a ser considerados cidadãos, com direitos pessoais e sociais garantidos.

No Brasil, o debate sobre os Direitos Humanos ganhou força nos últimos anos em diferentes dimensões sociais e em especial no âmbito educacional e da saúde mental. No campo da educação a discussão cresceu, sobretudo a partir da promulgação do Plano Nacional de Educação dos Direitos Humanos (PNEDH/2006) e da Lei 1.1525/2007, que são iniciativas importantes enquanto compromissos com a formação do educador ao lidar com este processo sistemático e multidimensional. Sendo assim, a Lei 11525/2007, que determina a inserção de conteúdos que tratem da temática dos Direitos Humanos no currículo do ensino fundamental, é uma importante conquista da sociedade brasileira que contribui para colocar em ação 
proposições do Estatuto da Criança e do Adolescente a partir do qual estes passam a ser vistos como sujeitos de direitos. No âmbito da saúde mental

[...] a luta pela Reforma Psiquiátrica pode ser considerada como parte da própria história de consolidação dos valores expressos na Declaração Universal dos Direitos Humanos, de 1948, da Organização das Nações Unidas. No Brasil, a Constituição Federal de 1988 incorporou preceitos da Declaração Universal, incluindo, em seu artigo $1^{\circ}$, a dignidade da pessoa humana como fundamento do Estado brasileiro (BRASIL [SDH], 2010, p. $4)^{5}$.

A reforma psiquiátrica, instituída no Brasil por meio da Lei 10216/2001, destaca a amplitude das ações de cuidado aos usuários e considera a necessidade dos mesmos serem considerados caso a caso, sem preconceitos de qualquer espécie. Estas diretrizes foram reafirmadas na terceira edição do Programa Nacional de Direitos Humanos - PNDH-3, lançado em 21 de dezembro de 2009 e assinado por 31 ministérios, que aborda o tema Saúde Mental em diferentes eixos e ações programáticas (ibidem). Em relação à Educação em Direitos Humanos, as contribuições para a IV conferência intersetorial de Saúde mental e Direitos Humanos destacam que este tema deve ser compreendido

[...] como um processo sistemático e multidimensional que orienta a formação de sujeitos de direitos, articulando várias dimensões. O PNDH-3 e - Plano Nacional de Educação em Direitos Humanos, que são os instrumentos normativos que orientam as políticas públicas nessa área, ressaltam a necessidade de se discutir o tema como um campo de conhecimento transdisciplinar nas escolas, universidades, instituições de atendimento e na mídia. Em 2006, foi instituído, pelo Ministério da Saúde em parceria com a Secretaria de Direitos Humanos, o Núcleo Brasileiro de Direitos Humanos e Saúde Mental, com o objetivo de fomentar mecanismos específicos para o acolhimento de denúncias e o apoio à pesquisa (BRASIL [SDH], 2010, p. 7).

Estes documentos juntam-se ao Estatuto da Criança e do Adolescente no sentido de promover os direitos humanos desta população e para consolidar o Sistema de Garantia de Direitos da criança e do adolescente. No entanto, ainda há grande dificuldade em implementar políticas concretas de enfrentamento, articular e fortalecer ações integradas para a proteção deste segmento da população, devido a diversas variáveis. Dentre as quais podemos destacar as consequências psíquicas decorrentes das situações da violação dos direitos de crianças e adolescentes que podem se expressar de diversas maneiras. Por exemplo, no âmbito do rendimento escolar, esses alunos podem apresentar dificuldades, explicadas tanto

${ }^{5}$ BRASIL. Secretaria de Direitos Humanos da Presidência da República. Saúde Mental e Direitos Humanos. Contribuições para a IV Conferência Nacional de Saúde Mental. Brasília, 2010. 
pela situação de stress à qual estão ou estiveram submetidos quanto pelo comprometimento do próprio funcionamento do pensamento e da memória. Desde Freud $(1908)^{6}$, sabemos que o despertar da curiosidade e o desejo de saber das crianças alimentam-se profundamente das experiências e investigações sobre si própria com as quais ela está envolvida. Nos casos em que a criança tem a percepção de si própria e do mundo perturbada por uma experiência cujo sentido the escapa, todo o funcionamento do psiquismo é afetado ${ }^{7}$. Entende-se que o não-dito ligado a situações traumáticas vividas pela criança se encontra não somente na origem da angústia, mas também pode contribuir para prejudicar algum aspecto do seu desenvolvimento.

Sendo assim, frente à violação dos direitos são necessárias ações que saiam da lógica da emergência e construam um percurso educativo social e de saúde, e que fortaleçam a relação entre o sistema de garantia de direitos e o sistema de saúde, para criar resultados sustentáveis de médio e longo prazo para os adolescentes. Pois, como dito anteriormente, foi a partir da criação histórica da adolescência como etapa da vida, foi possível pensá-la como campo de interesse e como categoria de direitos. Tal consolidação se materializa no relatório da Situação da Adolescência Brasileira 2011 lançado pelo Fundo das Nações Unidas para a Infância (UNICEF). A proposta, além de resgatar o direito de ser adolescente, enaltece a adolescência como etapa de vida, uma das mais "ricas fases da vida humana, repleta de possibilidades de aprendizagem, de experimentação, de inovação" (UNICEF, 2011).

\section{CONSIDERAÇÕES FINAIS}

Fazendo uma leitura retroativa podemos dizer que se hoje falamos de uma cultura de direitos do adolescente, a mesma só foi possível a partir da construção da adolescência como categoria. Como vimos, a concepção de desenvolvimento humano, a importância da biografia, as representações do foro íntimo como lugar de singularidade e verdade, tão faladas e defendidas hoje, levaram séculos sendo

\footnotetext{
${ }^{6}$ Freud, S. Sobre as teorias sexuais das crianças. (J. Salomão, Trad.). Edição Standard Brasileira das Obras Psicológicas Completas de Sigmund Freud (Vol. IX). Rio de Janeiro: Imago, 1908.

${ }^{7}$ Nesse sentido, é interessante a constatação de Jean Bergès (1999) em sua pesquisa com crianças com dificuldades de aprendizagem, ao verificar que, em um total de trinta crianças atendidas por transtornos da leitura, registravam-se nove assassinatos e sete mortes súbitas inexplicadas entre os familiares mais próximos a elas.
}

R. Inter. Interdisc. INTERthesis, Florianópolis, v.12, n.1, p.176-191, Jan-Jun. 2015 
construídas. $O$ trajeto individual da criança para o adulto entendido como fundamental ensejou toda uma discussão mais abrangente de direitos e deveres, políticas específicas, garantia dos direitos. Ou seja, apenas a partir da possibilidade de entendermos a adolescência como etapa única da vida, como trajetória importante e necessária aos seres humanos, é que podemos pensá-la como um direito de todos. Se houve um adiamento do momento no qual a criança deveria assumir a posição do adulto, foi porque justamente a própria visão do que era ser uma criança ou um adulto também veio a se modificar na modernidade. Tomando-os como objetos diferenciados, Ihes foi atribuído um mundo psíquico particular, foco de interesse e cuidados. Nesse sentido, foi somente a partir de uma nova compreensão do próprio humano que foi possível o surgimento da categoria de adolescência, com o consequente entendimento de que todos temos o direito de viver este estado e a criação de uma cultura de direitos. 


\title{
ADOLESCENCE, MODERNITY AND CULTURE OF RIGHTS
}

\begin{abstract}
:
This paper aims to present a historical discussion about the emergence of the concept of adolescence, the consequences and ramifications that such a perspective effects in creating a culture of rights. Born in the ideals of modernity, adolescence brings with it a certain conception of temporality related to the rise of individualism and the enhancement of human development as a career. It is only from a design trajectory needed to build the free and autonomous individual symbolized by the adult that becomes possible to reflect on the teenager as a subject of rights. Therefore, the emergence of adolescence as a category object of study and care also entails an entire comprehensive discussion of rights and duties culminating with the idea of being a teenager as a right.
\end{abstract}

Keywords: Adolescence. Modernity. Individualism. Freedom. Rights.

\section{Adolescencia, modernidad y cultura de los derechos}

\section{Resumen:}

El objetivo de este trabajo es presentar una lectura del origen de la categoría adolescencia, las consecuencias y ramificaciones que tal perspectiva efectiva en la creación de una cultura de derechos. Nacida en los ideales de la modernidad, la adolescencia trae consigo cierta concepción de la temporalidad en relación con el surgimiento del individualismo y de la apreciación del desarrollo como trayectoria humana. Es sólo a partir de una concepción de trayectoria necesaria para la construcción de un individuo autónomo y libre, simbolizado por el adulto, que es posible reflexionar sobre los adolescentes como sujetos de derechos. De ahí el nacimiento de la categoría adolescencia como objeto de estudio y cuidado también implica toda una discusión más amplia de los derechos y deberes que culminaron con la idea de ser un adolescente como un derecho.

Palabras clave: Adolescencia. Modernidad. Individualismo. Libertad. Derechos humanos. 


\section{REFERÊNCIAS}

ARIĖS, P. Lénfant et la vie familiale sous l'Ancien Régime. Paris: Plon, 1960. BERGĖS, J. A instância da letra na aprendizagem. Revista da APPOA (Associação Psicanalítica de Porto Alegre), ano IX, número 16, 1999.

BEZERRA JÚNIOR, B.; PLASTINO, C. A. (orgs.). Corpo, afeto, linguagem: a questão do sentido hoje. Rio de Janeiro: Rios Ambiciosos, 2000.

BEZERRA JÚNIOR, B. A retomada do futuro: tempo e utopia na subjetividade contemporânea. In: JOBIM E SOUZA, S. (org.). Mosaico: imagens do conhecimento. Rio de Janeiro: Rios Ambiciosos, 1989. p 81-95.

BRASIL. Secretaria de Direitos Humanos da Presidência da República. Saúde Mental e Direitos Humanos. Contribuições para a IV Conferência Nacional de Saúde Mental. Brasília, 2010.

BRASIL. Lei $n^{\circ} 11.525$ de 25 de setembro de 2007. Acrescenta § 50 ao art. 32 da Lei $n^{\circ}$ 9.394, de 20 de dezembro de 1996, para incluir conteúdo que trate dos direitos das crianças e dos adolescentes no currículo do ensino fundamental. Brasília, 2007.

BRASIL. Comitê Nacional de Educação em Direitos Humanos. Plano Nacional de Educação em Direitos Humanos. Brasília: Secretaria Especial dos Direitos Humanos, Ministério da Educação, Ministério da Justiça, UNESCO, 2006.

BRASIL. Lei Federal $n^{\circ} 8.069$, de 13 de julho de 1990. Dispõe sobre o Estatuto da Criança e do Adolescente e dá outras providências. Estatuto da Criança e do Adolescente. Brasília, 1990.

DUARTE, L. F. O culto do eu no templo da razão. Boletim do Museu Nacional. Número 41, 1983.

DUMONT, L. O individualismo - uma perspectiva antropológica da ideologia moderna. Rio de Janeiro: Rocco, 1985.

FIGUEIREDO, L. C. Modos de subjetivação no Brasil. São Paulo: Escuta, 1992. 
FOUCAULT, M. A escrita de si. In: O que é um autor? Lisboa, Passagens, 1992.

FREUD, S. Sobre as teorias sexuais das crianças. (J. Salomão, Trad.). Edição Standard Brasileira das Obras Psicológicas Completas de Sigmund Freud (Vol. IX). Rio de Janeiro: Imago, 1980. (Original publicado em 1908)

GIDDENS, A. As consequências da modernidade. São Paulo: UNESP, 1991.

HERBERT, M. Convivendo com adolescentes. Rio de Janeiro: Bertrand Brasil, 1991.

HURLOCK, E. B. Desenvolvimento do adolescente. Trad. Auriphebo B. Simões. São Paulo: McGraw-HilL, 1979.

MEAD, M. Adolescencia, sexo y cultura en Samoa. Buenos Aires: Paidós, 1984.

SEM, A. Desenvolvimento como liberdade. São Paulo: Companhia das Letras, 2008.

TOCQUEVILLE, A. (1835). A democracia na América. Belo Horizonte: Itatiaia, 1998.

TOURAINE, A. Crítica da modernidade. Petrópolis, Rio de Janeiro: Vozes, 2002.

UNICEF. $O$ direito de ser adolescente: oportunidade para reduzir vulnerabilidades e superar desigualdades. Brasília, DF: UNICEF, 2011. 182p.

Artigo:

Submetido em 28.07.2014

Aceito em 30.01.2015 